\title{
Licenciatura em educação do campo e interdisciplinaridade: a realidade como fim e a práxis como meio
}

Licensing in field education and interdisciplinarity: reality as an end and praxis as a means

\author{
Paulo Roberto de Sousa Silva \\ Raimundo Edson Pinto Botelho
}

Resumo: A partir de pesquisa documental e bibliográfica, o texto analisa a categoria interdisciplinaridade na Educação do Campo, tendo em vista aportar contribuições por ocasião da reestruturação dos Projetos Pedagógicos do Curso de Licenciatura em Educação do Campo, da Universidade Federal do Maranhão, em Bacabal. Além de um breve percurso histórico e uma revisão da literatura, partindo da crítica à disciplinaridade à crítica à interdisciplinaridade, o texto segue com uma retomada da Licenciatura em Educação do Campo em suas origens teórica e política, situando o lugar da interdisciplinaridade no currículo do curso, posicionando-se em favor da necessidade de uma abordagem interdisciplinar no ensino de conhecimentos produzidos interdisciplinarmente e para a compreensão da realidade do campo como totalidade, situando o conhecimento e a respectiva abordagem pedagógica como práxis. $E$ aponta como possíveis caminhos para a Interdisciplinaridade na Educação do Campo: a pesquisa e o trabalho como princípios educativos e a organização curricular por alternância, que se integram a partir de um plano de atividades organizador do trabalho coletivo interdisciplinar, orientado por eixos integradores representativos de fenômenos relevantes da realidade camponesa, tomada como objeto de estudo e intervenção pedagógica, através do ensino, pesquisa e extensão.

Palavras-chave: Educação do Campo; Interdisciplinaridade; Práxis.

\begin{abstract}
Based on documentary and bibliographic research, the text analyzes an interdisciplinary category in Rural Education, with a view to contributing through restructuring interviews of the Pedagogical Projects of the Rural Education Degree Course, at the Federal University of Maranhão, in Bacabal. In addition to a brief historical trace and a review of the literature, part of the criticism of disciplinarity and criticism of interdisciplinarity, the text follows a review of the Degree in Rural Education in its theoretical and political origins, placing the place of interdisciplinarity in the course curriculum, positioning itself in favor of the need for an interdisciplinary approach in the teaching of knowledge, using interdisciplinary skills and to obtain an understanding of the reality of the field as ears, placing knowledge and practical pedagogical approaches in practice. And it indicates as possible paths for Interdisciplinarity in Rural Education: research and work as educational principles and curricular organization through alternation, which are integrated from an activity plan that organizes interdisciplinary collective work, guided by representative integrators of individuals from public interest in the peasant reality, taken as an object of study and pedagogical intervention, through teaching, research and extension.
\end{abstract}

Keywords: Rural Education; Interdisciplinarity; Praxis. 


\section{Introdução}

Este texto foi produzido por ocasião da reestruturação dos Projetos Pedagógicos do Curso (PPC) de Licenciatura em Educação do Campo, nas terminalidades Ciências Agrárias e Ciências da Natureza e Matemática, do Centro de Ciências, Educação e Linguagens (CCEL), da Universidade Federal do Maranhão (UFMA), em Bacabal, que foi colocada como tarefa do Núcleo Docente Estruturante do Curso supra, desde o ano de 2017, primeiramente para atender a Resolução $n^{\circ}$ 2/2015 do Conselho Nacional de Educação e depois para atender a Resolução $n^{\circ}$ 2/2019 do mesmo Conselho, bem como a necessidade de ajustes decorrente da avaliação acumulada ao longo dos seus 11 anos de existência.

Neste contexto, considerando a relevância que a interdisciplinaridade ocupa nos projetos pedagógicos do curso, avaliou-se pertinente explicitar de forma qualificada as concepções e abordagens metodológicas defendidas, fazendo-se necessário o estudo e discussão coletiva em torno da temática, a fim de subsidiar o posicionamento institucional a ser expresso nos PPCs sobre as finalidades e as estratégias interdisciplinares implementadas em seu currículo.

Com o intuito de corroborar nesse sentido, além de um breve percurso histórico sobre a interdisciplinaridade, foi feito estudo sobre a legislação pertinente, especialmente as Resoluções que motivaram tal proposta e uma revisão da literatura trazendo algumas contribuições necessárias para fundamentar o debate acerca da questão, partindo da crítica à disciplinaridade à crítica à interdisciplinaridade.

Em seguida, com uma retomada da Licenciatura em Educação do Campo em suas origens teórica e política, e considerando os princípios e objetivos expressos nos PPCs em questão pretende-se situar o lugar da

interdisciplinaridade e sua relação com a disciplinaridade e a multidisciplinaridade no currículo da Licenciatura em Educação do Campo, posicionando-se em favor da necessidade de uma abordagem interdisciplinar no ensino de conhecimentos produzidos interdisciplinarmente e para a compreensão da realidade do campo como totalidade, situando o conhecimento e a respectiva abordagem pedagógica como práxis. 
Para tanto, propõe-se três possíveis caminhos: a pesquisa como princípio educativo; o trabalho como princípio educativo e a organização curricular por alternância, que se entrecruzam e multiplicam-se, mas integram-se a partir de um plano de atividades organizador do trabalho coletivo interdisciplinar, orientado por eixos integradores representativos de fenômenos relevantes da realidade camponesa, tomada como objeto de estudo e intervenção pedagógica, através do ensino, pesquisa e extensão.

\section{Da crítica à disciplinaridade à crítica à interdisciplinaridade}

É importante enfatizar que o processo de disciplinaridade surge como elemento imprescindível e fundamento do modo de produção capitalista em sua fase liberal. Naquela conjuntura, era necessário criar um conjunto de conhecimentos compartimentados e fragmentados que auxiliasse o processo e divisão do trabalho, imposto pelo modo de produção capitalista, em sua fase de Revolução Industrial. Do ponto de vista filosófico, o Positivismo cartesiano foi fundamental, tanto na explicação do mundo, quanto para alicerçar os princípios que orientaram o modo de produção capitalista.

A crise do liberalismo e a implementação dos regimes de acumulação fordista/taylorista acentuou esse processo, particularmente com 0 desenvolvimento da especialização produtiva. Sendo assim, era necessário garantir um modelo de educação disciplinar e seriada, para atender os desígnios e lógica do processo produtivo.

A crise do regime de acumulação fordista que se desenvolveu a partir dos anos de 1970 e as necessidades de expansão do capital impôs novas formas de organização do conhecimento que estava fragmentado em disciplinas. Nesse sentido, era necessário criar um mecanismo menos rígido para atender a nova demanda do mundo da produção. Sendo assim, a interdisciplinaridade surge como movimento de crítica e necessidade de resposta ao avanço do capitalismo, sobretudo, em sua fase neoliberal, caracterizada pelo regime de acumulação flexível, denominado toyotismo, que irá impactar a ciência e a educação, expressando-se tanto no campo da epistemologia quanto da pedagogia. 
Contudo, apesar dessa nova exigência, com o surgimento de novas áreas do conhecimento e do setor produtivo de base interdisciplinar, é importante enfatizar que não há um rompimento com a educação disciplinar e seriada, mas sua adequação ao novo padrão.

Do ponto de vista da literatura que fundamenta o processo histórico é importante analisar a obra de Japiassu (1976), pois, sua tese se fundamenta no argumento de que a interdisciplinaridade é uma solução para a fragmentação disciplinar e, nestas condições, para a fragmentação do saber. Do ponto de vista epistemológico, a fragmentação do saber tem levado o mundo a um desequilíbrio e a solução para este passaria, necessariamente, pela interdisciplinaridade.

No âmbito da educação, como parte do movimento de crítica à concepção tradicional realizada pelo escolanovismo, Fazenda (1979) defendeu que a interdisciplinaridade é, fundamentalmente, uma prática. A tese central da autora se baseia na ideia de que o caráter prático utilitário da interdisciplinaridade deve se sobrepor ao teoricismo. Neste sentido, a prática, além de viável é imprescindível para mudança na forma de conceber e construir o conhecimento a partir do sujeito. Neste contexto, a interdisciplinaridade não é ensinada, mas aprendida na prática, ou seja, aprende-se no momento quando se pratica, em que se vive. E cabe ao sujeito, por meio de seu esforço, aprender por meio da prática. No entender da autora, além de se sobrepor à teoria, a prática é condição sine qua non para a materialização da interdisciplinaridade.

Esta concepção foi duramente criticada por Jantsch e Bianchetti (1995), sobretudo, porque, além de descolar a interdisciplinaridade do movimento teórico para o movimento da prática, Fazenda transferiu a interdisciplinaridade única e exclusivamente para o sujeito. Nesse sentido, entendem que o processo de fragmentação do saber não pode ser superado, pela vontade e atitude interdisciplinar de um sujeito. Sobre este aspecto, os autores enfatizam que, apesar da disciplinaridade ter sido uma necessidade de um momento histórico, ela é uma imposição do momento atual. Na concepção dos autores, a fragmentação do conhecimento está diretamente ligada à fragmentação do trabalho, não sendo apenas uma questão epistemológica, mas uma imposição histórica. A interdisciplinaridade não pode ser vista como uma redentora da 
educação, mas como uma forma de integração das especialidades, quando esta se faz necessária.

Além da crítica à concepção de que a interdisciplinaridade seria o remédio que extirparia a patologia provocada pela fragmentação do saber, Veiga-Neto (1997) argumenta que a disciplinaridade não é somente um problema epistemológico, mas também um problema histórico, fruto das crises do mundo moderno e, dessa forma, não pode ser resolvido apenas no plano epistemológico e pedagógico, mas no plano da realidade, ou seja, a interdisciplinaridade é um problema teórico, mas também uma questão real.

Nessa mesma direção, Santomé (1998) afirma que a interdisciplinaridade é uma contingência histórica. Assim, a questão disciplinar está diretamente relacionada aos fundamentos do mundo industrial, ou seja, é produto histórico dos regimes de acumulação fordista/taylorismo. Desse modo, as mudanças tecnológicas que ocorreram na sociedade, sobretudo com a organização do trabalho globalizado, reestruturação produtiva, tendo o toyotismo como principal representante, fizeram com que o mercado passasse a necessitar de trabalhadores com uma capacitação mais ampla, competentes e capazes de desempenhar diferentes funções ao mesmo tempo. Nesse caso, a interdisciplinaridade surge com o objetivo de superar a fragmentação do saber e formar um trabalhador aberto a mudanças, solidário, democrático, polivalente, diferente do trabalhador especializado formado pelo sistema tradicional, disciplinar e seriado, característico do regime de acumulação fordista/taylorista.

No movimento de crítica da crítica, como um exímio intelectual orgânico, Frigotto (1992), com base no método dialético, argumenta que a interdisciplinaridade é uma necessidade, mas também é um problema. Como necessidade, a interdisciplinaridade funda-se no caráter dialético da realidade social que, além de una é diversa, bem como, na natureza intersubjetiva de sua apreensão. Como problema, o autor enfatiza os limites do sujeito que busca construir o conhecimento de uma determinada realidade, porque esta, ao mesmo tempo em que é muito dinâmica, dado o seu caráter histórico e processual, é complexa e só pode ser apreendida em sua totalidade, por meio de um movimento de síntese das múltiplas determinações. 
Diante disso, a revisão da literatura permite afirmar que a polissemia da categoria Interdisciplinaridade não é apenas uma questão de semântica. Antes, denota diferentes posicionamentos ideológicos, abrigados em concepções ontológicas, epistemológicas e pedagógicas diversas e, por vezes, divergentes, constituídas historicamente em meio a diferentes e contraditórios interesses sociais.

Em todo caso, refere-se ao conhecimento em sua produção ou ensino, na interação e mutualidade entre os campos disciplinares, distinguindo-se do conceito de transdisciplinaridade por não prescindir da organização disciplinar. É uma questão de atitude, pois pressupõe o diálogo entre diversos; mas não se restringe a isso, situando-se historicamente relacionada com a fragmentação do trabalho moderno, que não tem como ser resolvida apenas no plano epistemológico e pedagógico.

O decurso teórico corrobora, ainda, com a reflexão sobre o lugar da interdisciplinaridade no PPC de Licenciatura em Educação do Campo, exigindo um esforço criativo na proposição de estratégias pedagógicas, sintonizadas com as concepções filosóficas e políticas que fundamentam o curso e a Educação do Campo; e com a realidade concreta do campo como totalidade diversa e complexa, com ênfase na atualidade do trabalho camponês, sua organização e suas múltiplas relações.

\section{Licenciatura em educação do campo, interdisciplinaridade e realidade}

Os cursos de Licenciatura em Educação do Campo se constituem, no Ensino Superior brasileiro, na primeira década do século XXI, no processo de luta histórica dos movimentos sociais pela terra, sobretudo, da luta pela reforma agrária e por educação; na defesa de um projeto de campo fundado na

agricultura camponesa de base familiar e agroecológica; e de um projeto de educação centrado na formação omnilateral e promotor do território camponês, a Educação do Campo.

Nesta perspectiva é preciso reconhecer o campo como um espaço histórico de disputa, marcado na atualidade, por dois projetos antagônicos. De um lado, tem-se o campo do agronegócio, da mecanização da agricultura, da 
homogeneidade, da concentração fundiária, do monocultivo voltado para exportação, da ausência de sujeitos no campo; do outro, o campo como espaço da diversidade produtiva, de sujeitos, de cultura, o campo da agricultura camponesa de base familiar. Nesse contexto, essa realidade complexa e diversa precisa ser apreendida em sua unidade e diversidade, ou seja, em sua totalidade, por uma concepção que seja capaz de articular esse movimento em suas múltiplas dimensões, política, social, histórica, econômica e cultural.

Na mesma direção, é importante enfatizar que o campo possui uma organização escolar simultaneamente marcada pela negação e precariedade; e pela diversidade e complexidade, situando a escola do campo numa encruzilhada entre a luta pelo direito à educação, inclusive contra o fechamento de escolas; e a construção de um projeto de educação sintonizado com as perspectivas de futuro do campesinato, cujas raízes encontram-se nas experiências educativas concretas dos povos do campo e suas elaborações, como a escola multisseriada, que controversamente resiste; a criativa Pedagogia da Alternância, forjada pelos próprios camponeses; a Pedagogia do Movimento, concebida na luta social do Movimento dos Trabalhadores Rurais Sem Terra (MST) e inspirada nas contribuições da Pedagogia Socialista e da Pedagogia do Oprimido, além de outras diversas experiências vivenciadas no âmbito dos movimentos e organizações sociais, alinhadas com a formação omnilateral, construídas na organização coletiva, no trabalho como princípio educativo, na agroecologia e nas lutas sociais.

Conforme Caldart (2010), trata-se de transformar a escola, reconfigurando a forma escolar, potencializando sua relação com a vida e o trabalho, a partir da práxis como unidade teoria-prática que transforma a realidade no mesmo movimento da autotransformação humana decorrente do processo educativo.

Essa realidade concreta e dialeticamente utópica de campo e educação constituem os pilares da Licenciatura em Educação do Campo como um curso de formação de educadores que se justifica mediante a necessidade social e histórica de formação de um novo educador para uma nova escola, um novo campo, uma nova sociedade. 
Certamente que o referido curso precisará se debruçar sobre grandes desafios pedagógicos, dentre os quais Caldart (2011) enfatiza o tratamento a ser dado à profissionalização, considerando a preparação de educadores para um projeto de escola em construção e o papel do curso no vínculo orgânico com tais escolas e com os movimentos sociais nessa construção; a necessidade de se tomar o campo como objeto de estudo sistemático e rigoroso, em suas relações com as contradições sociais do modo de produção capitalista na atualidade; a organização do curso como um processo formativo orientado por uma visão alargada de educação, sintonizada com esse projeto de campo e escola; e o desafio de se construir estratégias pedagógicas que materializam o exercício da práxis dentro do próprio curso.

Nesse sentido, Molina e Sá (2012) afirmam que a organização multidisciplinar por área do conhecimento e a organização do currículo por alternância compartilham concepções ontológicas e epistemológicas que compreendem a realidade como totalidade complexa, possibilitando seu estudo por meio de abordagens que deem conta de apreendê-la nas suas contradições, no seu movimento histórico, na articulação intrínseca entre educação e os fenômenos da realidade do campo, na unidade teoria-prática.

Vale ressaltar, conforme enfatiza Caldart (2011), que a formação multidisciplinar por área foi incluída como um dos focos da profissionalização da Licenciatura em Educação do Campo, tendo em vista a necessidade de transformação da forma escolar atual, sobretudo, na construção de um vínculo mais orgânico entre educação escolar e realidade, superando a fragmentação curricular; e na reorganização do trabalho docente, marcado fundamentalmente pela cultura do trabalho individual e isolado dos professores.

Por isso, o curso proposto não é uma licenciatura disciplinar em educação, como são os cursos de Pedagogia, nem em outra disciplina específica das áreas do conhecimento; nem uma licenciatura interdisciplinar por área; mas, uma Licenciatura em Educação do Campo com organização multidisciplinar por áreas do conhecimento.

São os desafios da realidade objeto de formação do curso, portanto, que justificam sua organização multidisciplinar, tendo em vista a natureza do trabalho 
dos profissionais que pretende formar, para o trabalho docente multidisciplinar por área do conhecimento; bem como a necessidade de compreensão dessa realidade em sua totalidade e complexidade e da intervenção sobre a mesma, na perspectiva de sua transformação, que impõe a exigência pedagógica de abordagens interdisciplinares ou mesmo transdisciplinares.

Contudo, tanto a formação multidisciplinar precisa garantir o domínio das bases científicas e metodológicas específicas de cada disciplina que compõem as áreas de aprofundamento, quanto a própria integração interdisciplinar fica limitada mediante a falta de domínio dos fundamentos disciplinares específicos, requerendo, em ambos os casos, o estudo disciplinar.

O desafio, portanto, consiste na integração do trabalho pedagógico numa mesma totalidade incluindo disciplinas, práticas sociais, estudo, trabalho e organização coletiva na direção da construção de novas relações sociais e da formação omnilateral dos trabalhadores que Ihe corresponde, conforme afirma Caldart (2011).

Nessa proposição curricular, a interdisciplinaridade é requisitada pelas transformações na produção do conhecimento, que vem ocorrendo não somente na reestruturação produtiva capitalista, mas também pelas novas exigências do trabalho camponês contemporâneo, que demandam estudos de novos campos do conhecimento de caráter interdisciplinar, como a Agroecologia e a própria Educação do Campo, cuja produção científica articula disciplinas de diferentes áreas, integrando ciências da natureza e ciências humanas e sociais, evidenciando a importância da agroecologia na Licenciatura em Educação do Campo, não somente como uma disciplina, mas como um eixo transversal que precisa se materializar em componentes curriculares e estratégias pedagógicas interdisciplinares.

O esforço criativo na construção de arranjos curriculares interdisciplinares no PPC é, portanto, uma necessidade sócio-histórica decorrente da atualidade do trabalho e da vida no campo que exige novas soluções complexas na produção e socialização do conhecimento, ou seja, de ordem epistemológica e pedagógica, que não cabem nos limites de uma determinada disciplina. 
Justifica-se, ainda, como necessidade, conforme argumentou Frigotto (1992), diante do objetivo da Educação do Campo de tomar a realidade camponesa como objeto de estudo, em face do caráter dialético da realidade social que só pode ser apreendida em sua totalidade, dada a sua complexidade, por meio de um movimento intersubjetivo de síntese de múltiplas determinações.

Ou seja, na interdisciplinaridade como meio, através do qual os fenômenos relevantes da realidade atual são tomados como objeto de estudo coletivo, fundado no diálogo entre as bases teóricas e metodológicas das várias áreas do conhecimento, com o fim de compreender a realidade em suas múltiplas relações, potencializando a capacidade de intervenção dos sujeitos sobre a mesma, na perspectiva de sua transformação.

Em síntese, a argumentação que vem sendo tecida visa sustentar três afirmações: a importância das disciplinas, sobretudo, os seus fundamentos teórico-metodológicos; a opção de organização multidisciplinar por área do conhecimento das licenciaturas em educação do campo, tendo em vista projetar uma nova organização do trabalho pedagógico nas escolas do campo; e a interdisciplinaridade como necessidade em virtude do estudo de conhecimentos produzidos interdisciplinarmente e da natureza complexa da realidade que se busca compreender, que exige o esforço de uma práxis intersubjetiva e interdisciplinar.

\section{Possíveis caminhos da interdisciplinaridade na licenciatura em educação do campo}

O ponto de partida é esse duplo entendimento: da interdisciplinaridade, enquanto abordagem pedagógica, como um meio necessário ao estudo de conhecimentos produzidos interdisciplinarmente, a partir das exigências da atualidade sócio-histórica do campo, no âmbito do território camponês, tais como a agroecologia e a própria educação do campo; e da interdisciplinaridade como uma necessidade para compreensão da realidade em sua totalidade dialética, cujo conhecimento se constitui na unidade teoria-prática, e cuja compreensão objetiva transformar essa realidade da vida, do trabalho, da educação, da escola do campo. Em ambos os casos, a chave comum é a realidade e a necessidade 
de compreensão de suas múltiplas determinações tendo em vista sua transformação, reivindicando uma concepção de interdisciplinaridade como práxis.

Referida abordagem traz implícito alguns elementos, potenciais mobilizadores de sua materialização: conhecer a realidade, tomar a realidade, em sua totalidade, como objeto de estudo (o campo como território e cultura; os sujeitos do campo e suas lutas; o trabalho camponês, suas relações e tecnologias, a agroecologia; a educação e a escola do campo; as políticas públicas...). Diante disso, como conhecer a realidade, senão pela pesquisa? A pesquisa interessada, engajada. A pesquisa como atividade interdisciplinar.

Mas, conhecer nesse paradigma justifica-se no movimento de transformação. Conhecer para transformar. Agir sobre a realidade construindo um novo campo, uma nova escola, uma nova sociedade. Denota que o estudo sobre a realidade requer uma prática. Uma prática que gera reflexão, teoria. Uma prática refletida, que não se reduz à aplicação da teoria, teoria-prática, práxis, que transforma o sujeito e a realidade simultaneamente. Fundada no trabalho como princípio educativo, o trabalho socialmente necessário, a ação extensiva como práxis. A prática como atividade interdisciplinar.

Importa, então, conhecer e transformar a realidade num percurso acadêmico fundado numa formação científico-filosófica vinculada com a realidade em sua totalidade. Vínculo esse sem o qual não é possível conhecer concretamente, muito menos transformar. Conhecer-transformar, teoria-prática, trabalho-educação, escola-realidade são diferentes expressões de um binômio que expressa a fratura historicamente construída da divisão social do trabalho manual e intelectual. E no horizonte de uma educação para emancipação faz-se necessário tensionar em favor da superação dessa ruptura, na construção de uma unidade dialética, na perspectiva da práxis. Nesse sentido, a organização curricular por alternância pode ser uma estratégia interdisciplinar mediadora da práxis.

Desse modo, vislumbram-se aqui três caminhos que requerem uma abordagem interdisciplinar no curso de Licenciatura em Educação do campo: o estudo da realidade, tomando a pesquisa como um princípio educativo; a prática 
em unidade com a teoria como concepção de conhecimento, assumindo o trabalho como um princípio educativo; e o vínculo efetivo entre educação e campo, alternando os espaços/tempos da formação acadêmica (Tempo Universidade) e da vivência comunitária (Tempo Escola-Comunidade) como um contínuo cuja alternância mantém unidade pedagógica dos tempos/espaços educativos.

Caminhos que se entrecruzam e multiplicam-se numa infinidade de percursos possíveis, exigindo planejamento integrado e organização coletiva do trabalho docente, sendo possível abordá-los separadamente apenas para uma exposição didática de aspectos que se integram como um processo complexo.

\section{Estudar a realidade: a pesquisa como princípio educativo}

Ao tomar a realidade como base para produção do conhecimento como um princípio básico, a Licenciatura em Educação do Campo reconhece o campo em sua totalidade como objeto de estudo e da formação do educador e assume um desafio pedagógico, cujo desenlace não cabe nos limites da tradicional organização disciplinar, requerendo novos arranjos interdisciplinares nos quais a pesquisa assume lugar privilegiado, numa relação intrínseca com o ensino, no sentido defendido por Freire (2016, p. 30) para o qual "não há ensino sem pesquisa e pesquisa sem ensino" e por Demo (2002, p. 50) ao afirmar que "se a pesquisa é a razão do ensino, vale o reverso, o ensino é a razão da pesquisa. $O$ importante é compreender que sem pesquisa não há ensino", posicionando a pesquisa como princípio científico e educativo, constituinte da formação do ser social e fundamento para sua emancipação.

A versão atual dos PPCs de Licenciatura em Educação do Campo em discussão, embora não explicitem a pesquisa como um princípio educativo, já apontam em seus objetivos a integração ensino, pesquisa e extensão num processo dialético de ação-reflexão-ação; e o desenvolvimento de pesquisas e experiências pedagógicas, tendo em vista a intervenção qualitativa na realidade das escolas do campo (UFMA, 2014). Além disso, expressam em diversos elementos de sua organização curricular e da prática docente a importância e integração da pesquisa com o ensino na formação do educador do campo. 
A recorrência de atividades de pesquisa como recurso didático nos vários componentes curriculares, em especial as atividades do Tempo EscolaComunidade; os inventários da realidade; o caderno de reflexão; os projetos de pesquisa e iniciação científica; o percurso de pesquisa monográfica, passando pelos Seminários de Pesquisa e culminando num Trabalho de Conclusão de Curso (TCC), dentre outras estratégias pedagógicas, são exemplares da relevância da pesquisa e do esforço em integrá-la ao ensino e à extensão. Contudo, a ausência de um posicionamento explícito da pesquisa como princípio educativo e da integração científica desses diversos elementos, a partir de teorias pedagógicas que compreendam o currículo em sua complexidade e como unidade, restringe as potencialidades da pesquisa na direção dos objetivos citados.

Assumir a pesquisa como um princípio educativo, considerando a realidade como objeto de estudo, requer um planejamento integrado que articule as diversas estratégias de investigação num percurso formativo, conferindo unidade e intencionalidade, a partir das necessidades postas pela realidade e seus desafios epistemológicos que, por sua vez, decorrem de necessidades sociais.

O objetivo fundamental do referido planejamento interdisciplinar é compreender os fenômenos da realidade em sua totalidade e historicidade, como complexidade concreta, sabendo-se que tais fenômenos estão interligados e somente podem ser compreendidos na sua complexidade, com suas relações. São, portanto, os diferentes fenômenos relevantes da atualidade em suas correlações que interessa compreender, através de uma abordagem interdisciplinar e intersubjetiva.

Nesse sentido, corroboram as principais teorias pedagógicas que fundamentam a Educação do Campo, a saber a Pedagogia Freireana, com a proposição dos "Temas Geradores", a Pedagogia Socialista e a organização curricular por "Sistemas de Complexos" e os instrumentos pedagógicos da Pedagogia da Alternância, a exemplo dos "Planos de Estudo" e do "Caderno da Realidade". 
Propositivamente, considera-se que a concretização da pesquisa como princípio educativo no currículo do curso poderia viabilizar-se pela organização do percurso formativo a partir de eixos integradores, representativos de aspectos da realidade camponesa, relevantes para a formação do educador do campo e potenciais articuladores de conjuntos de componentes curriculares e estratégias pedagógicas em unidades curriculares, para as quais agregariam colaborativamente os conteúdos e metodologias das diversas áreas do conhecimento, o que requer um esforço de reorganização e articulação dos componentes da matriz curricular e do trabalho pedagógico, rompendo os muros disciplinares, no intuito da compreensão da realidade, conforme mencionam Cunha e Silva (2016).

Definidos e organizados os aspectos da realidade em grandes categorias objetos de investigação e intervenção pedagógica, como temas geradores ou complexos de estudo, aqui denominados de eixos integradores, seguir-se-ia a associação de disciplinas, projetos e atividades acadêmicas específicas que se articulariam coletivamente em torno de cada eixo integrador, considerando a pertinência dos objetivos, conteúdos e metodologias específicas em relação aos fenômenos da realidade implicados, constituindo um percurso comum de formação que avançaria progressivamente para os interesses individuais de estudo, culminando no TCC e nas práticas de estágio.

Cada conjunto de fenômenos articulados em um eixo integrador, com os componentes curriculares integrados e seus respectivos docentes, formariam coletivos pedagógicos cujo trabalho interdisciplinar se orientaria por planos de atividades integradas, no sentido dos sistemas de complexos de estudos da pedagogia socialista, envolvendo o estudo dos fundamentos teóricometodológicos das disciplinas; os fenômenos relevantes da realidade atual; o trabalho socialmente necessário e os processos de auto-organização dos sujeitos.

Desse modo, os planos de atividades integradas, no que se refere à dimensão da pesquisa, envolveriam estudos e atividades de pesquisa das disciplinas e áreas do conhecimento; a inserção em projetos e grupos de estudo e pesquisa; atividades interdisciplinares do Tempo Escola-Comunidade; e os 
instrumentos de registro e sistematização, tais como os inventários da realidade, os cadernos de reflexões e a organização de portfólios; dentre outras estratégias relacionadas à pesquisa.

Vale ressaltar que a organização curricular e do trabalho pedagógico não se reduz aos planos integrados aqui propostos, sendo este apenas parte de um planejamento mais amplo onde ocorrem outros processos pedagógicos multidisciplinares ou no âmbito singular das disciplinas e demais componentes curriculares.

Transformar a realidade: a unidade teoria-prática e o trabalho como princípio educativo

Conhecer a realidade, no quadro epistemológico em que essa discussão se tece, não pode ser uma tarefa unicamente teórica, nem desinteressada. Por outro lado, também não se reduz ao empirismo raso, cuja prática redunda num ativismo pragmático movido por interesses imediatos; mas, como filosofia da práxis, no sentido apontado por Marx nas Teses sobre Feuerbach, para o qual interpretar o mundo é necessário, mas insuficiente. Pois, o que importa é transformá-lo.

Sobre este aspecto é imprescindível o exercício concreto dos princípios basilares do Projeto Pedagógico do Curso, dentre os quais, o trabalho como princípio educativo, a unidade teoria-prática e a educação para transformação social, conforme preconizam os autores, como Makarenko, Pistrak, Shulgin, Gramsci e os contemporâneos Luiz Carlos de Freitas, Gaudêncio Frigotto, Demerval Saviani e Roseli Caldart.

Organizar o trabalho pedagógico, tanto nas Licenciaturas em Educação do Campo, quanto nas escolas do campo, nesse prisma, requer fundamentalmente pensar outra concepção de trabalho que se alarga para além do trabalho acadêmico ou restrito simplesmente à relação dual entre trabalho e educação. Para a realidade camponesa caracterizada pela negação do direito à educação em que os camponeses foram obrigados a optar pelo trabalho ou pelo estudo, esta superação é imprescindível. 
Considerando ainda a forma como a escola e a universidade têm concebido trabalho e educação como atividades antagônicas, em que geralmente o processo educativo é visto como abstrato e sem significado para o mundo produtivo em que os camponeses estão inseridos; é preciso superar essa dualidade, integrando educação e trabalho como um todo dialético.

Neste contexto, é preciso entender o trabalho, enquanto ação humana que transforma a natureza e o próprio homem (Marx), gera riqueza e contribui para que o próprio homem se emancipe. Desse modo, é preciso pensar em outra concepção de trabalho aqui defendida como sendo aquela baseada no trabalho socialmente necessário e elemento de emancipação humana, na concepção cunhada por Shulgin (2013), que compreende o trabalho desenvolvido pela escola, no caso a Universidade, orientado por necessidades sociais e que produz resultados concretos; pedagogicamente relevante; e adequado às condições físicas e intelectuais dos estudantes, que é educativo por ser constituinte do ser humano como ser social e soma-se ao desafio histórico de superação da cisão entre trabalho manual e intelectual.

Assumir o trabalho como princípio educativo, educando pelo trabalho e para o trabalho, como se apresenta nos princípios do PPC da Licenciatura em Educação do Campo não se restringe à educação profissional; antes, trata-se da formação do ser humano trabalhador, conhecedor na teoria e na prática dos fundamentos e métodos das principais formas de trabalho num dado momento histórico, na perspectiva da educação politécnica. Precisa vincular-se ao contexto real do trabalho produtivo, inserindo o discente nas problemáticas concretas vivenciadas pelos trabalhadores, no âmbito da tecnologia, da organização coletiva da produção e das relações de trabalho, sob o crivo das ciências.

Novamente, aqui se depara com a necessidade de uma abordagem interdisciplinar e de organização coletiva do trabalho docente, uma vez que a prática numa relação intrínseca com a teoria, e as necessidades concretas do trabalho, em situação real de produção, não se comportam nos limites de uma única disciplina ou do trabalho docente individual. 
Nesse caso, a materialização do trabalho como princípio educativo no currículo do curso de Licenciatura em Educação passa pela subordinação de algumas estratégias pedagógicas, já previstas nos PPCs, aos referidos princípios e concepções que o norteiam.

Ao situar o campo, seus territórios, culturas e sujeitos; as questões nele implicadas, suas organizações e lutas sociais; a educação, a escola e as políticas públicas de educação do campo; o trabalho e suas relações, a agroecologia e as tecnologias camponesas, como objeto de estudo da Licenciatura em Educação do Campo e da formação do educador, na perspectiva da práxis, fica evidente o lugar da prática, ressignificada como trabalho socialmente necessário, sem a qual não é possível conhecer concretamente. A prática como força material para transformação da realidade.

Nessa perspectiva, a alternância e o desenvolvimento local, pilares da Pedagogia da Alternância, requerem um planejamento que, simultaneamente, integre os tempos educativos numa unidade teoria-prática e articule conteúdos e métodos de diversas disciplinas, numa abordagem interdisciplinar, em torno de uma prática social concreta, considerando as múltiplas relações que compreendem os fenômenos da realidade em sua totalidade.

Nesse sentido, mais uma vez justifica-se a proposição de uma organização coletiva do trabalho docente, em torno de planos de atividades integradas, como estratégia pedagógica interdisciplinar que organiza, não somente o percurso formativo em torno da pesquisa; mas também, em torno do trabalho, da prática em unidade com a teoria, com a pesquisa; a partir de eixos integradores que orientariam uma trajetória coletiva e organizaria as trajetórias individuais que se seguiriam com os Estágios Curriculares Obrigatórios e os TCC's.

O planejamento individual ou multidisciplinar dos componentes curriculares se articulariam com planejamentos coletivos interdisciplinares que, dentre outros elementos, organizariam a prática pedagógica como componente curricular e as atividades de extensão na forma de componente curricular, ambas exigências das diretrizes curriculares para formação de professores, podendo integrar, ainda, projetos de iniciação à docência, de residência pedagógica, de 
extensão e outras iniciativas que tenham uma dimensão prática como as místicas, a organicidade das turmas e as atividades coletivas de autosserviço necessárias no Tempo Universidade.

\section{Vínculo efetivo entre educação e campo: organização por alternância como unidade pedagógica dos tempos educativos}

Por fim, um terceiro caminho, para a abordagem interdisciplinar proposta, passa pela especificidade do curso de Licenciatura em Educação do Campo, no que lhe dá origem: a Educação do Campo. Dito melhor, a intrínseca relação entre Educação e Campo reivindicada a partir dessa concepção.

Do que já foi exposto nas seções anteriores, a Licenciatura em Educação do Campo tem centralidade no campo como objeto de teoria e prática, encontrando na pesquisa e no trabalho como princípios educativos possibilidades pedagógicas para concretização da unidade educação-campo, como particularidade da unidade teoria-prática.

Nesse sentido, a Pedagogia da Alternância oferece uma organização curricular que viabiliza essa articulação, possibilitando um percurso formativo que integra o lugar da educação formal aos espaços de vivências do campo, Universidade e Escola-Comunidade, como dois tempos/espaços que alternamse num único processo formativo, integrando teoria-prática, cuja complexidade demanda um arranjo curricular e organização pedagógica interdisciplinar em coerência com referida concepção.

Para tanto, o ponto de partida precisa ser a organização coletiva do trabalho pedagógico, do planejamento à sua execução, para o qual sugere-se a construção de planos de atividades integradas compondo os coletivos de trabalho interdisciplinar, a partir do vínculo entre as disciplinas, seus objetivos, conteúdos programáticos e metodologias; projetos de pesquisa, ensino e extensão; e demais atividades acadêmicas específicas, com os eixos integradores organizadores dos fenômenos da realidade do campo que seriam objeto de estudo e prática. Vale ressaltar que a organização do trabalho coletivo requer o fortalecimento de uma cultura dialógica entre os sujeitos, explicitando 
suas concepções, compartilhando informações e buscando as interações disciplinares possíveis no trabalho colaborativo.

Além da organização coletiva do trabalho docente, a efetivação da alternância requer o uso sistemático de instrumentos pedagógicos que possibilitem o acompanhamento do Tempo Escola-Comunidade e sua integração com o Tempo Universidade, considerando o que historicamente vem se consolidando nas experiências dos Centros Familiares de Formação por Alternância (CEFFAs), dentre os quais destacam-se os Planos de Estudo, que permitem aos estudantes organizar o estudo/intervenção na realidade ao longo do seu percurso de formação; os Cadernos da Realidade ou Cadernos de Reflexão, onde registram sistematicamente os fatos relevantes de sua experiência educativa e os aprendizados construídos pela reflexão; o uso de Portfólios como forma de documentação e organização dos materiais produzidos ou utilizados ao longo da trajetória acadêmica; os Seminários ou Assembleias no início e final de etapas, a fim de organizar a transição, assegurando continuidade dos tempos educativos e o compartilhamento dos aprendizados. Em todos os casos, acumulando para a produção do TCC e das vivências do Estágio Curricular Obrigatório.

Nessa proposição, as atividades do Tempo Escola-Comunidade e a respectiva carga-horária se destinariam, prioritariamente, para atividades integradas interdisciplinares, instituídas como práticas como componente curricular e atividades de extensão na forma de componente curricular, não somente cumprindo as exigências das diretrizes curriculares específicas, mas como trabalho socialmente necessário, efetivando a relação teoria-prática, por meio de um movimento dialético caracterizado pela dinâmica ação/reflexão/ação, conforme preconiza Gimonet (2007). Aqui é importante enfatizar que não se trata de uma relação dual em que o primeiro se torna ponto de partida para chegar-se ao outro, mas trata-se de um movimento sincrônico em que ação/reflexão/ação estão dialeticamente articulados por meio do movimento da práxis.

Considerando ainda aquilo que Luckesi (2014) argumentou quando afirmou que para formar interdisciplinarmente é preciso que o educador seja 
formado interdisciplinarmente, acredita-se que a referida proposta permite construir espaços e momentos, simultaneamente, formativos para os educadores e estudantes do curso.

Por fim, há de se considerar que, se tratando de trabalho socialmente necessário, as atividades de pesquisa e trabalho/prática/extensão desenvolvidas no âmbito da Licenciatura em Educação do Campo referem-se, prioritariamente, às práticas sociais do trabalho docente na educação básica, sobretudo nos anos finais do ensino fundamental e médio, nas áreas de aprofundamento do curso e nos processos de gestão da escola do campo; no trabalho de educação popular nas organizações camponesas; e no trabalho camponês, da produção agrícola, de base agroecológica, que se desenvolve concretamente imbricado na complexidade da dinâmica social do campo, com seus desafios e lutas protagonizados pelos trabalhadores camponeses, educadores do campo e suas organizações, com os quais é imprescindível a construção de relações interinstitucionais.

\section{Considerações}

Movidos pela necessidade de qualificar as concepções, finalidades e metodologias para uma abordagem interdisciplinar nos PPCs de Licenciatura em Educação do Campo da UFMA, partiu-se de um estudo teórico revisando a literatura sobre o tema, a partir do qual chegou-se ao reconhecimento da polissemia da categoria interdisciplinaridade, como expressão de diferentes concepções ontológicas, epistemológicas e pedagógicas, exigindo um posicionamento crítico em relação à disciplinaridade e à interdisciplinaridade.

Em geral, o termo refere-se ao conhecimento em sua produção ou ensino, na interação e mutualidade entre os campos disciplinares, não prescindindo da organização disciplinar. Pressupõe o diálogo entre diversos, mas é historicamente determinado pela fragmentação do trabalho moderno, que não tem como ser resolvida apenas no plano epistemológico e pedagógico.

$O$ estudo de documentos e textos teóricos que fundamentam as origens do curso de Licenciatura em Educação do Campo no Brasil e das versões atuais dos PPCs em discussão apontam para necessidade de coerência entre a 
abordagem interdisciplinar adotada e as concepções filosóficas e políticas que fundamentam o curso e a Educação do Campo, de modo geral, e com a realidade concreta do campo como totalidade diversa e complexa, com ênfase na atualidade do trabalho camponês, sua organização e suas múltiplas relações.

Nesse sentido, a argumentação tecida buscou sustentar três afirmações: a importância das disciplinas, sobretudo, os seus fundamentos teóricometodológicos; a opção de organização multidisciplinar por área do conhecimento das Licenciaturas em Educação do Campo, tendo em vista projetar uma nova organização do trabalho pedagógico nas escolas do campo; e a interdisciplinaridade como necessidade em virtude do estudo de conhecimentos produzidos interdisciplinarmente e da natureza complexa da realidade que se busca compreender, que exige o esforço de uma práxis intersubjetiva e interdisciplinar.

Particularmente em relação à abordagem pedagógica interdisciplinar no curso, destacaram-se duas possibilidades: como meio necessário ao estudo de conhecimentos produzidos interdisciplinarmente, a partir das exigências da atualidade sócio-histórica do campo, no âmbito do território camponês, tais como a agroecologia e a própria educação do campo; e da interdisciplinaridade como uma necessidade para compreensão da realidade em sua totalidade dialética, cujo conhecimento se constitui na unidade teoria-prática, e cuja compreensão objetiva transformar essa realidade da vida, do trabalho, da educação, da escola do campo. Em ambos os casos, a chave comum é a realidade e a necessidade de compreensão de suas múltiplas determinações tendo em vista sua transformação, reivindicando uma concepção de interdisciplinaridade como práxis.

Diante disso, vislumbram-se três caminhos orientadores dos possíveis arranjos curriculares para uma abordagem interdisciplinar no curso de Licenciatura em Educação do campo, na perspectiva citada: o estudo da realidade, tomando a pesquisa como um princípio educativo; a prática em unidade com a teoria como concepção de conhecimento, assumindo o trabalho como um princípio educativo; e o vínculo efetivo entre educação e campo, alternando os espaços/tempos da formação acadêmica (Tempo Universidade) e 
da vivência comunitária (Tempo Escola-Comunidade) como um contínuo cuja alternância mantém uma unidade pedagógica dos tempos/espaços educativos.

Caminhos que se entrecruzam e multiplicam-se numa infinidade de percursos possíveis, exigindo planejamento integrado e organização coletiva do trabalho docente, sendo possível abordá-los separadamente apenas para uma exposição didática de aspectos que se integram como um processo complexo.

Para tanto, o ponto de partida precisa ser a organização coletiva do trabalho pedagógico, do planejamento à sua execução, para o qual sugere-se a construção de planos de atividades integradas compondo os coletivos de trabalho interdisciplinar, a partir do vínculo entre as disciplinas, seus objetivos, conteúdos programáticos e metodologias; projetos de pesquisa, ensino e extensão; e demais atividades acadêmicas específicas, com os eixos integradores organizadores dos fenômenos da realidade do campo.

Vale ressaltar que tais eixos, não se restringiriam a um elenco de assuntos tematizados teoricamente, mas a uma delimitação e organização de aspectos da realidade, situando o campo, seus territórios, culturas e sujeitos; as questões nele implicadas, suas organizações e lutas sociais; a educação, a escola e as políticas públicas de educação do campo; o trabalho e suas relações, a agroecologia e as tecnologias camponesas, como objetos de estudo e de intervenção pedagógica da Licenciatura em Educação do Campo e da formação do educador, na perspectiva da práxis.

Desse modo, os planos de atividades integradas teriam como objetivo fortalecer a integração entre os diversos componentes curriculares, potencializando a relação teoria-prática, a organização multidisciplinar do trabalho pedagógico e a abordagem interdisciplinar, articulando ensinopesquisa-extensão, a partir de fenômenos relevantes da realidade camponesa e da educação do campo, em particular, da escola do campo.

Os referidos planos integrariam grupos de componentes curriculares das três áreas do conhecimento; as 400 horas de prática como componente curricular e as atividades de extensão na forma de componente curricular, prioritariamente na carga horária do Tempo Escola-Comunidade; os 
componentes de estágio curricular obrigatório; os componentes de seminários de pesquisa e TCC; Projetos de pesquisa, ensino e extensão.

Certamente que a abordagem interdisciplinar proposta não se viabiliza sem o dispêndio de tempo e esforço em conhecer a realidade do campo, os fenômenos relevantes e suas relações; em analisar os planos de ensino dos componentes curriculares e as possibilidades de interação; em manter uma dinâmica sistemática de formação continuada dos docentes e uma organização coletiva do trabalho pedagógico, pautada no diálogo honesto e qualificado entre os pares e no trabalho colaborativo.

\section{Referências}

BRASIL. Resolução CNE/CES n 7, de 18 de dezembro de 2018. Estabelece Diretrizes para a Extensão na Educação Superior Brasileira.

Resolução CNE/CP $n^{\circ}$ 2, de 20 de dezembro de 2019. Define as Diretrizes Curriculares Nacionais para a Formação Inicial de Professores para a Educação Básica e institui a Base Nacional Comum para a Formação Inicial de Professores da Educação Básica (BNC-Formação).

CALDART, Roseli Salete (org.). Caminhos para transformação da escola: reflexões desde práticas da Licenciatura em Educação do Campo. São Paulo: Expressão Popular, 2010, pág. 127-154 (Cadernos do Iterra n. 15, setembro 2010).

. Licenciatura em Educação do Campo e projeto formativo: qual o lugar da docência por área. In: MOLINA, Mônica Castagna; SÁ, Laís Mourão (orgs.). Licenciaturas em Educação do Campo: registros e reflexões a partir das experiências-piloto (UFMG; UnB; UFBA e UFS). Belo Horizonte: Autêntica Editora, 2011(Coleção Caminhos da Educação do Campo; 5). p. 95 - 121.

CUNHA, Maria Bernadete de Melo Cunha; SILVA, José Luís de Paula Barros. Complexos temáticos na formação de professores do campo. Educar em Revista, Curitiba, Brasil, n. 61, p. 171-188, jul./set. 2016. Disponível em: https://www.scielo.br/pdf/er/n61/1984-0411-er-61-00171.pdf. Acesso em: 08 jul. 2020.

DEMO, Pedro. Pesquisa: princípio científico e educativo. 12. Ed. São Paulo: Cortez, 2006.

FAZENDA, Ivani Catarina Arantes. Integração e Interdisciplinaridade no ensino brasileiro: efetividade ou ideologia. São Paulo: Loyola, 1979.

FREIRE, Paulo. Pedagogia da autonomia: saberes necessários à prática educativa. 54ª ed. Rio de Janeiro: Paz e Terra, 2016. 
Pedagogia do oprimido. Rio de Janeiro: Paz e Terra, 1983.

FRIGOTTO, Gaudêncio. A interdisciplinaridade como necessidade e como problema nas ciências sociais. In.: Educação e Realidade. Porto Alegre: 18(2), $\mathrm{jul} / \mathrm{dez}, 1992$, p. 63-72.

GIMONET, Jean-Claude. Praticar e Compreender a Pedagogia da Alternância dos CEFFAs. Petrópolis, Paris: Vozes, Associação Internacional dos Movimentos Familiares de Formação Rural, 2007.

JANTSCH, Ari Paulo, BIANCHETTI, Lucídio (orgs.). Interdisciplinaridade: para além da filosofia do sujeito. Petrópolis, RJ: Vozes, 1995.

JAPIASSU, Hilton. Interdisciplinaridade e Patologia do Saber. Rio de Janeiro: Imago, 1976.

KRUPSKAYA, Nadejda Konstantinovna. A construção da pedagogia socialista: escritos selecionados. São Paulo: Expressão Popular, 2017.

LUCKESI, Cipriano. Ludicidade e formação do educador. Entreideias, Salvador. v. $3 . \quad$ n. 2014. Disponível em: https://portalseer.ufba.br/index.php/entreideias/article/download/9168/8976.

Acesso em: 12 mai. 2020.

MOLINA, Mônica Castagna; SÁ, Laís Mourão. Licenciatura em Educação do Campo. In: CALDART, Roseli Salete et al (Org.). Dicionário da Educação do Campo. São Paulo e Rio de Janeiro: Escola Politécnica de Saúde Joaquim Venâncio; Expressão Popular, 2012. p.468-474.

SANTOMÉ, Jurjo Torres. Globalização e interdisciplinaridade. Porto Alegre: Artmed, 1998.

SHULGIN, Viktor Nikolaevich. Rumo ao politecnismo (artigos e conferências). São Paulo: Expressão Popular, 2013.

UNIVERSIDADE FEDERAL DO MARANHÃO. Projeto Político-pedagógico do Curso de Licenciatura em Educação do Campo - Ciências da Natureza e Matemática. Bacabal/MA, 2014.

VEIGA-NETO, Alfredo. Currículo e Interdisciplinaridade. In: MOREIRA, Antonio Flávio B. (Org.). Currículo: questões atuais. Campinas: Papirus, 1997 p. 59102.

\section{Sobre os autores}

\section{Paulo Roberto de Sousa Silva}

pauloroberto.ce@gmail.com

Possui Mestrado em Educação Brasileira, pela Universidade Federal do Ceará (UFC); Especialização em Trabalho, Educação e Movimentos Sociais, pela Escola Politécnica de Saúde Joaquim Venâncio, da Fundação Osvaldo Cruz 
(Fiocruz); Especialização em Educação do Campo e Desenvolvimento, pela Universidade de Brasília (UnB); e Licenciatura Plena em Pedagogia, pela Universidade Federal do Ceará (UFC). Atua como Professor Assistente, no Curso de Licenciatura em Educação do Campo, da Universidade Federal do Maranhão (UFMA). Tem experiência e interesse, principalmente, em Educação Popular e Movimentos Sociais; Educação e Escola do Campo; Trabalho e Educação; e Juventude.

Raimundo Edson Pinto Botelho

raimundobotelho@yahoo.com.br

Possui graduação em Geografia pela Universidade Federal do Maranhão (2001). Mestrado em Geografia pela Universidade Federal do Rio Grande do Norte (2010). Doutorado em Políticas Públicas pela Universidade Federal do Maranhão em 2017. Atua como docente da Universidade Federal do Maranhão, na Coordenação do Curso de Licenciatura em Educação do Campo, Campus III, Bacabal/MA. Suas produções estão voltadas para Geografia, nas áreas de Agrária e Econômica, dando ênfase aos aspectos ligados à dinâmica territorial, das lutas sociais, Políticas Públicas, relações de trabalho e Educação do Campo. 